\title{
Promoting Student's Online Engagement with Communication Tools
}

\author{
Shuyan Wang \\ The University of Southern Mississippi
}

\begin{abstract}
This case study investigated students' engagement and learning experiences in online courses through Blackboard CE6 (Course Management System). The meaning that students gave to their learning experiences and the problems they encountered were also investigated in order to understand how students learn in a technology-enriched learning environment. Data were collected through open-ended survey questions, participant observations, and document analyses from three online instructional technology graduate courses where students used threaded discussion, live classroom, chat room, and email for online communication and interaction. Findings indicated that students' engagement was promoted by using various communication tools although student preferred discussion board and email to other tools. This study also illustrated the strengths and weaknesses of each tool and discussed the issues of using these tools as well as student'perspectives on using these tools to promote their interaction and collaboration.
\end{abstract}

Keywords: engagement, interaction, communication, online learning, threaded discussion.

\section{Background}

Web-based education is quickly changing the foundation of higher education by impacting current university practices and policies. As more courses and programs in higher education are being converted to online delivery, educators need to be concerned about how to maintain the quality of instruction for the online courses as well as motivating student engagement in the virtual classrooms. In this paper, engagement mainly refers to student interaction and cooperation in the online environment. Studies (Dittmer, 2010; Wang \& Hsu, 2009) indicate that online learning environment lacks a sense of community and social interaction among students. The inferior interaction between instructor and students, as well as among students, causes a lack of engagement of the students which are critical to student learning (Hemp,
Woollen, \& Humiston, 2009). Therefore, the effectiveness of communication among students is very important in making the online course successful. However, students have different perspectives on what makes their communication and interaction work best because of their different personalities and learning styles.

According to Allen and Seaman (2010), over 5.6 million students were taking at least one online course during the fall 2009 which excessed the total higher education student population. Nearly thirty percent of higher education students take at least one course online (Allen \& Seaman, 2010). Another statistic showed that the percentage of online US college course offered has grown $13 \%$ in 2009 , which was $20 \%$ higher than the previous years. The rate for admission in online courses has increased to one in four students from one 
in ten in 2002. The survey also indicates that more than two million students around the age group of 13-22 take all their courses online and another two million take some online courses (http://www.topcollegecourses.com).

This trend is reflected at the university where the study has been conducted. The university has pushed moving traditional face-toface courses and programs online. Currently, it offers four undergraduate online programs, twelve graduate online programs, and eight hybrid graduate programs, in addition to over 600 online courses offered each term. The new strategies based on improving student access and convenience through online courses help increase student enrollment and reduce financial barriers. The university has a policy of waiving out-of-state fees when enrolled in online classes. As a result, student retention is higher than previous years. However, issues of online teaching and learning have merged as more students take online courses. First of all, not all instructors are trained to teach online. Second, not all students are fit to take online courses because of their learning styles. Therefore, dropouts from online classes occur every term. Finally, even though most students complete the online courses, they might miss the effectiveness of interaction and communication found in traditional face-to-face classrooms.

After the WebCT course management system was upgraded to Blackboard CE6 (BbCE6) course management system, more tools were made available for instructors and students to use for improved communication and interaction. As a result, educators faced new challenges in effectively using these tools. With the current functions in BbCE6, students enjoyed the flexibility in gaining knowledge and skills by stepping outside the tradition of isolated courses and adopting more interdisciplinary approaches via applying technologies. However, the communication tools operated differently due to the particular context of each activity the people were involved with, the different purposes and expectations, the varying personal and professional backgrounds and concerns, and the level of familiarity with the technologies. Hence, further studies on these aspects needed to be conducted.

\section{Purpose of the Study}

To successfully implement Web-based instruction, instructors need to understand the critical interaction issues that may result from the size of the group, knowledge of other participants, learner experience, task clarity, ownership of the task, need for system usage, type of system available, and prior experience with computer-mediated communication. Investigating student and faculty online teaching and learning experiences, and obtaining their perspectives of the issues on interaction tools can provide a better understanding of effective Web-based instruction.

The purpose of this study was to examine and describe student and instructor experiences in graduate Web-based courses where interaction and collaboration between students were motivated by synchronous (same time but different places) and asynchronous (different time and different places) communication tools. This study investigated communication tools used in the class to better understand the issues involved from the students' perspective as well as the instructor's perspective. Student experiences and the meaning students gave to their experiences were also investigated to understand student behavior in using different communication tools. Research questions included:

1. What were students' learning experiences in using communication tools in BbCE6?

2. What were the perspectives of students using different communication tools in BbCE6? 
3. How did the usages of these tools influence student learning outcomes?

This study is significant in that it will provide first-hand and detailed information on the experiences, perceptions, and reflections of the students who used various communication tools in the online courses. The results of this study can be used by online teachers to determine what communication tools to use and how to use them properly to motivate students' collaboration and engagement. This study will also provide empirical evidence for the future research that can be beneficial for online teachers, curriculum developers, and instructional designers in their efforts to target collaborative online learning environment.

\section{Methodology}

A qualitative case study forms the methodological framework of this study. The case study results in a rich and holistic account of a phenomenon anchored on real life situations and offers insight into student communication and interactions while participating in an online learning class.

The research settings were three online Instructional Technology (IT) graduate courses offered through BbCE6. The first class was Research in Instructional Technology (Course A) which was offered in spring 2009 (16 weeks) with 7 students enrolled. Course A discussed steps of conducting qualitative research, which was a writing intensive course. The second class Telecommunications in Education (Course B) was offered in summer 2009 (10 weeks) with 13 students enrolled. Course $\mathrm{B}$ examined hardware, software, and utilization of telecommunication technology in education, which was a hand-on course. The third course Distance Learning Systems (Course C), was offered in summer 2009 (10 weeks) with 9 students enrolled. Course $\mathrm{C}$ introduced graduate students to distance learning models, theo- retical frameworks, and practical applications, which required students to design an online course. These courses were chosen because the researcher taught those courses and it was convenient for her to collect data. Participants were the students enrolled in these courses, including 29 masters and doctoral students. These students were majoring or minoring in IT which meant that they had taken quite a few IT courses so that they were experienced with basic technology applications and familiar with most tools, such as most popular communication tools and authoring applications. Students accessed course materials such as the syllabus, instructional materials, schedule, assignments, rubrics, and the like in Blackboard CE6. Communication tools used in these courses included email, discussion board, chat, live classroom, and voice board.

Data collection included participant observations, open-ended survey questions, and documentations of the course to ensure the triangulation of the data. Open-ended survey questions were included in students' course reflections. For instance, students were asked to answer the following questions in their course reflections: (a) Which communication tool did you use most: email, discussion board, live classroom, or chat room? From your experience, explain the advantages and disadvantages of each communication tool, and (b) How did you like the interaction between you and your peers, and between you and the instructor? Explain in detail. As the instructor of these online courses, the researcher had the opportunity to observe students' participation in all course activities as well as students' struggles when they encountered problems. The observation proved what students said in the reflection was what they did in class. Documentation in this study included the discussion postings, weekly announcements, and the tracking records of student activity. Documentation analysis provided deeper under- 
standing on student's reflections and instructor's observation.

Data analysis procedures for this study included organizing the data, generating categories, themes and patterns, and writing the final report. The researcher put together documents, archival records, participants' reflections, and the instructor's journal in order to organize what she experienced, heard, saw, and read. The various data sources allowed the researcher to triangulate her observations and interpretations of the participants' learning experience.

\section{Findings and Discussions}

Findings from this study showed that students were satisfied with the communications among their peers and with the instructor. All participants indicated a positive experience of the interaction and collaboration in these online courses. They felt closely connected with their peers and instructor. They were comfortable asking questions and communicating with other students. Most students stated that interaction with peers provided them the opportunity to learn from other resources; they learned a lot from peers through interaction. They also mentioned that interacting and communicating with peers required a large amount of self-motivation. Findings will be discussed on the stu- dent's perspective of discussions, emails, chat, and live classroom.

\subsection{Students' Perspectives on Discussions}

Threaded discussion was one of the main communication tools embedded in BbCE6. The instructor posted a question to start a threaded discussion, and students participated in the discussion by answering the question and commenting on other students' responses. All posts were listed under each thread and students could click the title to read the post and make comments.

In these online courses, the instructor posted two or more questions that related to the book chapters or a project to help students understand the content of that week. The discussion questions were posted on Sundays and locked on the following Wednesday. Students were expected to reply to the original instructor-made postings before/on the Friday of the assigned week, and read/comment on at least three colleagues' postings before it was locked. Students had to answer the questions thoughtfully with detailed support from their own experiences, opinions, and readings. Their comments to peers' responses should be meaningful and thoughtful.

Table 1: Students' Participation in Discussions

\begin{tabular}{llllllll}
\hline \multirow{2}{*}{ Class } & \multicolumn{3}{c}{ Messages Read } & \multicolumn{7}{c}{ Messages Posted } \\
\cline { 2 - 8 } & $\boldsymbol{A}$ & $\boldsymbol{H}$ & $\boldsymbol{L}$ & $\boldsymbol{R}$ & $\boldsymbol{A}$ & $\boldsymbol{H}$ & $\boldsymbol{L}$ \\
\hline Course A (7S, 16W) & 3389 & 8998 & 448 & 52 & 77.5 & 120 & 37 \\
Course B (13S, 10W) & 1903 & 5501 & 125 & 28 & 44 & 70 & 24 \\
Course C (9S, 10W) & 776 & 3034 & 290 & 24 & 30 & 45 & 7 \\
\hline
\end{tabular}

Notes: $\mathrm{S}=$ Students; $\mathrm{W}=$ Week; $\mathrm{A}=$ Average number of reading/posting; $\mathrm{H}=$ Highest number of reading/posting; $\mathrm{L}=$ Lowest number of reading/posting; $\mathrm{R}=$ Required Posting 
Table 1 indicated that students in all three classes were very active in the threaded discussions. The average postings were higher than the required postings for each class. Findings showed that some students were more active than others. The same was true with reading posts. Figures in table 1 also indicated that most students read others' posts more than once before they would provide comments. An interesting phenomenon the researcher noticed was that some students liked reading others' posts, but were reluctant to provide comments. Therefore, they had a very high record in reading posts, but a very low record in postings. Of course, the researcher also found a couple students who just wanted to meet the requirements and they did not post more than required.

According to the participants, the threaded discussions helped them share ideas of research and technology applications, understand the text and technology integration, finish projects, and understood the benefit from each other's personal experiences. Most students stated that written responses took more thought and time than verbally commenting on a topic, which resulted in more in-depth discussion and critical thinking. They also admitted that responses to the discussion questions and comments on peers' responses gave them time to organize their ideas and abbreviate their responses. At the same time, quite a few students complained that some postings were too long and they had to spend a lot of time to read all the postings on the discussion board. They especially did not like to read the posts which were published very late. Students also mentioned some technical problems that existed in BbCE6 such as viewing every posting in a new pop-up window, which was "awkward and time-consuming."

The findings from this study aligned with Hewitt's study in 2003, in which he found threaded discussions in distance learning helped (a) facilitate ongoing class discussions on a topic/theme, (b) share ideas, drafts, and finished projects with each other, and (c) solicit comments/critical feedback (Hewitt, 2003).

\subsection{Students' Perspectives on Email}

Email was one of the most frequently used communication tools in these classes. In addition to the weekly announcements, the instructor sent notices to class through emails. Although students could post their questions to the discussion board, some students preferred to email the instructor with personal and course related questions. This was indicated in table 2. For instance, instructor sent 129 emails to students in Course B in ten weeks, but only 59 in Course $\mathrm{C}$ in the same time. The reason for this big difference was that more students were enrolled in course B than Course C and more mini-projects were assigned in Course $\mathrm{B}$ than Course C. As a result, more questions emerged in Course B.

Table 2: Students' Use of Emails

\begin{tabular}{|c|c|c|c|c|c|c|c|}
\hline \multirow{2}{*}{ Class } & \multicolumn{3}{|c|}{ Emails Read } & \multicolumn{3}{|c|}{ Emails Sent } & \multirow[b]{2}{*}{$T E$} \\
\hline & $A$ & $\boldsymbol{H}$ & $L$ & $A$ & $\boldsymbol{H}$ & $L$ & \\
\hline Course A $(7 \mathrm{~S}, 16 \mathrm{~W})$ & 96 & 200 & 56 & 29 & 53 & 8 & 126 \\
\hline Course B $(13 \mathrm{~S}, 10 \mathrm{~W})$ & 74 & 168 & 22 & 22 & 37 & 6 & 129 \\
\hline Course C (9S, 10W) & 27 & 54 & 10 & 7.8 & 12 & 3 & 52 \\
\hline
\end{tabular}

Notes: $\mathrm{S}=$ Students; $\mathrm{W}=$ Week; $\mathrm{A}=$ Average number of emails sent/read; $\mathrm{H}=$ Highest number of emails read/sent; $\mathrm{L}=$ Lowest number of emails read/sent; $\mathrm{TE}=$ Emails sent by the teacher 
According to most of the participants, email was more convenient than other communication tools because this asynchronous communication tool gave them the freedom to ask questions at anytime. Students could forward the BbCE6 email to their personal email account so that they could receive and check emails there or even from smart phones. However, they had to sign-in to BbCE6 for email replies, which was the only drawback. Sometimes when the instructor received emails regarding the requirement of an assignment or a project related question, which she felt was important and should be clarified to all, she would respond to the whole class. As this happened frequently, some students might overlook the emails sent from the class, because they thought they know the solution or the requirements. As a result, they might miss important information sent from the instructor. Some participants indicated in their reflections that too many emails sent from the instructor made their experience more difficult to pay attention.

Findings from this study indicated that email system was easy and convenient to use, but had to be used wisely. For instance, an appropriate email heading would help students understand whether they needed to read the email or not.

\subsection{Student's Perspectives on Other Commu- nication Tools}

Other communication tools such as chat rooms, voice board, and live classroom were set up on the course site. These tools were optional for student use. Both chat and live classroom were synchronous communication tools which required students to be present at the same time to talk to one other. The main difference between chat and live classroom was that students could see each other through a webcam when they talked in the live classroom, but can only message or talk in a chat room. These tools were appropriate for students' group work when they wanted to achieve an immediate response or a decision. The voice board was an asynchronous communication tool. Students could record their voice messages and leave them on the voice board or send them to their group members as email attachments.

Table 3: Students' Participants in Other Tools

\begin{tabular}{lllllll}
\hline \multirow{2}{*}{ Class } & \multicolumn{2}{c}{ Chat Usages } & \multicolumn{2}{c}{ Voice Board Usages } & \multicolumn{2}{c}{ Live Classroom Usages } \\
\cline { 2 - 7 } & $\boldsymbol{A}$ & Total & $\boldsymbol{A}$ & Total & $\boldsymbol{A}$ & Total \\
\hline Course A (7S, 16W) & 7.6 & 53 & 6.4 & 45 & 4.1 & 25 \\
Course B (13S, 10W) & 5.9 & 77 & 6.1 & 79 & 5.3 & 69 \\
Course C (9S, 10W) & 1.8 & 16 & 1.1 & 10 & 1.2 & 11 \\
\hline
\end{tabular}

Notes: $\mathrm{S}=$ Students; $\mathrm{W}=$ Week; $\mathrm{A}=$ Average number of usages

Generally speaking, students in this study did not use these tools heavily, as shown in table 3. Students in Course B used these tools a little bit more than students in the other two classes because they needed to explore and experience the different communication tools in their class projects. In addition, they needed to communicate with their group members for various group projects. In contrast, students in Course $\mathrm{C}$ and Course A did not have that kind of need so they hardly used these tools. 
Although students in all three classes did not use chat, voice board, and live classroom frequently, they did describe their experiences and thoughts on the usages of these tools in their reflections. Most students admitted that using chat and live classroom to communicate with their group members enabled them to know their group members better. Most students prefer to hear and see the other person they were communicating with. Some students stated that chat with peers was a truly bonding experience, "I heard the voice and remember their voices as I read e-mails from them." Most students mentioned that knowing the faces that go with the names and personalities brought them closer in the virtual learning environment.

Findings from this study showed that most students did not like to use chat and live classroom because group members could not find a suitable time to meet online. Most students had a full-time job during the day time and took care of their children during evenings and weekends. They enjoyed the flexibility of studying on their own time and could not stand any set class meetings, even once a week, because that gave them stress and restriction. This finding corroborates previous studies (Chang, 2009) in that learners prefer to use email and discussion boards over online chat, because online chat requires synchronous communication.

\subsection{The Influence on Students' Learning Outcomes}

Findings indicated that students received great benefits from peer interactions. Students stated that reading others threaded discussion and viewing peer projects helped them rethink and revise their own projects. The results of this study indicated that appropriate use of the communication tools helped students interact and collaborate with peers closely in online courses, which in turn, provided them the opportunity to learn from other resources than just the textbook and the instructor. During the threaded discussion, students brought their own experiences of technology integration which were easily understood by their peers than from reading textbooks. As one student mentioned in her reflection,

One of the highlights I took from our discussion board and this course was peer editing of research papers. I really learned a lot from my peer's comments and was able to utilize their suggestions to build a strong paper. This was the first course I have ever shared this kind of information and found it to be very helpful. (Student J)

Using the discussed communication tools made students more involved in class activities. In most cases, the active students in threaded discussion gained good grades because (a) discussion participation accounted for $15-20 \%$ of the total grade, and (2) these students were self-motivated and good at time management. In fact, most "A" students were the ones who were very active in threaded discussions, always the first to post their answers, and provided detailed and thoughtful comments to peers' responses. This first group of students was willing to share their thoughts and kept the threaded discussion moving with meaningful input. In contrast, there were a few students who frequently read other students' answers and comments but did not provide comments. For instance, there was one student who viewed over two thousand posts, but published only about ten posts. In addition, they did not post their primary answers on time. This second group of students had problems to manage their time in finishing other assignments as well. As a result, their grades were not good. There were also a third group of students who had very strong technology background, good time management skills, and could finish all assignments according to the requirements with extra help, but they did not post more than required. They earned good grades, but they were not active 
students because they did not want to read and comment other's posts more than needed. They thought it was a waste of time because they knew the content very well and did not need to learn from others' posts. This finding indicated that, generally speaking, the most active students in threaded discussion easily achieved a good grade because they managed their time well, were active in all other activities, gained most knowledge and skills, and had positive learning experiences.

In contrast with discussion, more email communication received from a student indicated more problems that the student had with the course content or assignments. Students would email the instructor or a group member for help when they felt confused about the assignment. Some students were very nervous in the online classes so that they would email the instructor frequently. For instance, one student always sent emails to the instructor whenever she felt uncertain about the assignment. She once sent over ten emails to the instructor within a single day. The instructor could feel the student's struggle in this class. Interaction with the instructor really helped her understand the content and gained technology skills from this class as indicated in her reflection.

\subsection{Issues in Using Communication Tools and Online Interaction}

Findings from this study showed that there were some issues and concerns that students had with the discussed communication tools. The first issue that appeared was that email and discussion did not provide the same level of interaction as face-to-face meetings, so misunderstandings were more likely to occur because human communication was over $90 \%$ nonverbal. Several students indicated the concern in their reflections. As student R stated, threaded discussion emphasized reading and writing skills, rather than speaking and listening. It required more of learner's own respon- sibility and attention than the auditory way of providing and exchanging information. Threaded discussion was more formal due to the fact that students needed to type with written language, rather than using oral language. Student $\mathrm{C}$ mentioned the misunderstandings due to the lack of nonverbal communication cues that resulted in a failure to share meanings. The discussion might be off the point. Therefore, instructor's timely involvement and guidance were very important to keep the discussion on the right track.

The second issue was the heavy work load in weekly discussion. Almost all students were very active in answering the questions and commenting on peer's work in the first few weeks. But, some students slowed down in discussion when they started working on other projects. Quite a few students mentioned that some students did not post the answers on time which delayed their completion of the assignment of discussion because they could not comment on their peer's posts which were not published. Therefore, instructors should adjust the schedule for the discussion. The purpose of threaded discussion was to help the student understand content of the text so that they could finish assignments based on the content. Thus, it may work better if more threaded discussions were required at the early stage of the term and the times of discussion were reduced later in the term so that students could concentrate on their projects or other assignments.

The third issue was that some student's answers to the threaded questions and comments to other postings were too simple or not thoughtful or helpful to others. As student R stated, some students only summarized chapters without their own thoughts, which made it difficult for their readers to build upon the discussion. At the same time, some students' comments were meaningless. This finding confirmed previous studies (Lobry de Bruyn, 2004, Thomas, 2002) that learner participa- 
tion in threaded discussions was unequal and of varying quality. Findings from this study also proved two items in Tu's (2000) list of issues that required attention for a successful online interaction. They were (1) misunderstanding due to lack of non-verbal cues and failure to share meanings within system boundaries; and (2) lost in threaded messages as well as heavy workload (e.g., heavier reading load for online learners, time-consuming process of moderating class conferences, daily individual interactions).

\section{Conclusion}

Learning is an activity of performing collective social and interpretive behaviors among learners within their environment (Dewey, 1916). This study showed that students who were active in threaded discussion were also the students who submitted their assignments on time and most likely earned a higher final grade because these students were self-motivated and good at time management which was very important in online courses. In contrast, the students who were slow in threaded discussion were most likely students who could barely finish other assignments on time. These students struggled more at the end of the term because they had no time left to catch up with others in finishing all required postings and assignments. A positive online interaction not only increases student motivation and engagement of learning, but also promotes critical thinking and productiveness.

This study demonstrated that efficient communication and interaction were key factors ensuring the success of online courses, and using different communication tools created a flexible learning environment. However, the instructor should provide enough instruction and a set of criteria in using each communication tool and completing assignments. Instructors should set the maximum of devoted online time and think about students' schedule, as well as their efforts devoted to the course to prevent overload. To enhance the quality and quantity of student participation in online interaction, teacher's immediate involvement in discussion is important. This result is supported by a previous study (Tu, Blocher, and Gallagher, 2010) that providing students with discussion tools do not necessarily result in an effective learning environment. Integrating effective instructional strategies made the difference.

Most students admitted that they spent more time in an online class than in a similar traditional face-to-face class because they had to click and view every link to make sure that they did not miss any important information. But, they enjoyed the flexibility of the online class. This was also the reason why asynchronous communication tools were more popular than synchronous communication tools. However, if students could not manage their time well, they might face the problems as students who were slow in responding the threaded discussions did. Therefore, student had to think about their learning style, personality, and time management skills before deciding to take an online course instead of a face-to-face course.

\section{References}

Allen, E., \& Seaman, J. (2010). Class differences online education in the United States. Needham, MA: Sloan-C. Retrieved April 16, 2011, from http://www.sloanconsortium.org/publications/survey/pdf/class_ differences.pdf

Chang, C-W. (2009). Efficacy of interaction among college students in a Web-based environment. Journal of Educational Technology Development and Exchange, 2(1), 17-32. 
Dewey, J. (1961). Democracy and education. New York: MacMillan Company.

Dittmer, J. (2010). Immersive virtual worlds in university-level human geography courses. International Research in Geographical and Environmental Education, 19, 139154.

Hemp, R., Woollen, S., \& Humiston, S. (2009). A comparative analysis of student engagement, learning, and satisfaction in lecture hall and online learning settings. The Quarterly Review of Distance Education, 102, 207-218.

Hewitt, J. (2003). How habitual online practices affect the development of asynchronous discussion threads. Journal of Educational Computing Research, 28 (1), 31-45.

Thomas, M. J. W. (2002). Learning within incoherent structures: The space of online discussion forums. Journal of Computer Assisted Learning, 18, 351-366.

Tu, C., Blocher, M., \& Gallagher, L. (2010). Asynchronous network discussions as organizational scaffold learning: threaded vs. flat-structured discussion boards. Journal of Educational Technology Development and Exchange, 3(1), 43-56.

$\mathrm{Tu}, \mathrm{C}$. (2000). Critical examination of factors affecting interaction on CMC. Journal of Network and Computer Applications, 23, 39-58.

Wang, S. K., \& Hsu, H. (2009). Using the ADDIE model to design Second Life activities for online learners. TechTrends, 53, 76-81.

\section{Contact the Author}

Shuyan Wang, Ph.D.

Instructional Technology

The University of Southern Mississippi

E-mail: shuyan.wang@usm.edu 